\title{
Como a epistemologia, os seminários clínicos e a psicopatologia psicanalítica podem contribuir para a psicopatologia fenomenológica
}

Nelson Ernesto Coelho Junior ${ }^{1}$

Resumo: Este texto procura apresentar, inicialmente, o problema epistemológico determinado pelas tensões entre a dimensão universal e a dimensão singular dos fenômenos humanos. A seguir, procura indicar as contribuições da psicopatologia psicanalítica e do exercício dos seminários clínicos psicanalíticos para o problema epistemológico apontado anteriormente.

Palavras-chave: epistemologia, psicopatologia psicanalítica, seminário clínico, fenomenologia.

\section{How epistemology, clinical seminars and the psychoanalytic psychopathology can contribute to the phenomenological psychopathology.}

Abstract: As a first step this paper seeks to present the epistemological problem determined by the tensions between the universal dimension and the singular dimension of human phenomena. As a second step, seeks to show the contributions of the psychoanalytic psychopathology and of the exercise of psychoanalytic clinical seminars for the epistemological problem mentioned above.

Keywords: epistemology, psychoanalytic psychopathology, clinical seminars, phenomenology.

Nas duas últimas décadas enfrento o desafio da transmissão clínica da psicanálise e do ensino de um pensamento clínico. Uma parte desse desafio tem sido criar as pontes necessárias entre as dimensões mais universalistas da teoria e as dimensões mais singulares da experiência clínica cotidiana. Sempre procurei evitar a sobreposição da grade teórica sobre a experiência vivida, na mesma medida em que procurei evitar a valorização excessiva da experiência emocional, principalmente quando acompanhada de uma recusa fóbica a todo e

\footnotetext{
${ }^{1}$ Endereço: Instituto de Psicologia da USP. Av. Prof. Mello Moraes, 1721. CEP 05508-030. São Paulo, Brasil. E-mail: ncoelho@usp.br.
} 
Como a epistemologia, os seminários clínicos e a psicopatologia psicanalítica podem contribuir para a psicopatologia fenomenológica.

qualquer esforço teórico. Por isso, passei a valorizar o modelo de discussão de casos clínicos, os seminários clínicos e a discussão psicopatológica que os acompanha, como a forma mais produtiva de transmissão e ensino da psicanálise.

Começarei a tratar do tema por duas passagens bastante conhecidas e citadas do filósofo francês Merleau-Ponty que serviram de bússola nesses últimos anos, principalmente por seu caráter crítico ao posicionamento fundacionista dos projetos filosóficos que o antecederam:

Entre o conhecimento científico e o saber filosófico que o recoloca sempre na presença de sua tarefa, não pode haver rivalidade. Uma ciência sem filosofia não saberia, ao pé da letra, do que fala. Uma filosofia sem exploração metódica dos fenômenos chegaria apenas a verdades formais, isto é, a erros. Fazer metafísica não é entrar num mundo de conhecimento separado, nem repetir fórmulas estéreis como estas de que nos servimos aqui - é ter experiência plena dos paradoxos que indicam, é verificar sempre de novo o funcionamento discordante da intersubjetividade humana, é procurar pensar até o fim os mesmos fenômenos investidos pela ciência, restituindo-lhes somente sua transcendência e estranheza originárias (Merleau-Ponty, "Le Metaphysique dans l'homme”, in: Sens et non-sens, 1948 [1966], Paris: Nagel, p. 170-171).

Alguns anos depois, Merleau-Ponty voltaria a esse tema para afirmar que não se deve apenas dizer que a filosofia é compatível com a sociologia [representando aqui uma das formas de ciência], mas sim, que lhe é necessária, como lembrança contínua de suas tarefas e cada vez que o sociólogo [cientista] volta às fontes vivas de seu saber, ao que nele opera como meio para compreender as formações culturais mais afastadas dele, faz filosofia espontaneamente... A filosofia não é um certo saber, é a 
vigilância que não nos deixa esquecer a fonte de todo saber (MerleauPonty, “Le Philosophe et la Sociologie". In: Signes, 1960, Paris: Gallimard, p. 138).

O foco de Merleau-Ponty recai nesses textos nos embates que opõem Filosofia e ciência (e suas questões epistemológicas e ontológicas). Para o que nos interessa aqui, quando pensamos no campo da Psicopatologia Fenomenológica e as formas de se estabelecer as interfaces desse campo com a Filosofia e a Psicanálise, parece-me importante ter claro a que Filosofia nos referimos e o que entendemos por Psicanálise.

De um lado, a Filosofia que nos interessa é a fenomenológica, evidentemente, com sua ênfase ora na dimensão hermenêutica de cada existência, ora na dimensão carnal e desejante (como sugeriu recentemente Rudolf Bernet, 2013), mas sempre com um forte apelo aos aspectos intersubjetivos da experiência humana como, aliás, está bem explícito na primeira passagem de Merleau-Ponty que acabei de citar. De outro lado, quanto à Psicanálise e sua inesgotável contribuição para o domínio intrapsíquico, quero enfatizar que o que me interessa é o pensamento psicopatológico e clínico que busca colocar em cena as relações entre o intersubjetivo e o intrapsíquico.

Como se sabe, uma das questões recorrentes nas investigações fenomenológicas em psicopatologia é a que se refere à passagem da dimensão ontológica para a dimensão ôntica, ou dito de outro modo, a passagem das questões que envolvem as bases filosóficas de uma antropologia fenomenológica para a investigação empírica, que caracteriza a prática com os pacientes. Yves Pélicier, na apresentação da tradução da obra de Wolfgang Blankenburg, La perte de l'évidence naturelle, utiliza uma variação para se referir a esse tema (a base husserliana do pensamento de Blankenburg e o paradigma maior do ser humano esquizofrênico): "Esse ser é um caso particular do ser do qual fala a antropologia fenomenológica. Pode-se a seu respeito empregar a expressão ontologia regional, mas o enfoque é empírico. Está em relação direta 
Como a epistemologia, os seminários clínicos e a psicopatologia psicanalítica podem contribuir para a psicopatologia fenomenológica.

com o que a medicina pode trazer ao conhecimento por observação do 'homem doente'" $^{\prime \prime}(1991$, p. 7).

Uma das formas de enfrentar os problemas anunciados por MerleauPonty e Pélicier é dar um passo atrás e pensar se a querela dos métodos do final do século XIX, que opõe interpretação (ou compreensão) à observação (explicação), pode nos ajudar a clarear essas questões. Ou seja, escutamos e observamos em psicanálise ou mesmo em uma entrevista psiquiátrica eventos vividos (uma verdade histórica) ou apenas diferentes narrativas? É possível abandonar por completo o desejo de descobrir um fato ou uma força original desencadeadores de uma determinada forma de viver, para simplesmente substituí-los por uma interpretação de narrativas, com ou sem uma base filosófica que sustente o modelo interpretativo? Como já apontou o psicanalista norte-americano Roy Schafer (1983), não há jamais acesso imediato (não mediado) aos eventos da vida de um paciente, já que esses eventos têm existência apenas por meio de relatos, por meio de narrativas. Mas isso, por si só, anula a existência de fatos? Longe de assistirmos à resolução final de um complexo debate como esse, testemunhamos áreas de saber como a Psicologia, a Psiquiatria e a Psicanálise, cindidas entre as sedutoras tentações de se filiar seja ao modelo explicativo das ciências naturais (Naturwissenschaften), seja ao modelo compreensivo (ou hermenêutico) das assim chamadas Geisteswissenschaften (ciências do espírito ou humanas), como postulado por Dilthey no século XIX. Ou, ainda, como sugeriu o contemporâneo de Dilthey, Wilhelm Windelband (1894), cindidas entre as ciências nomotéticas (as que permitem a generalização do conhecimento) e as idiográficas (as caracterizadas pelo conhecimento de um fenômeno singular).

Acompanho, a seguir, algumas ideias do psicanalista Renato Mezan (2014, p. 549-550 e p. 552), em um texto recente chamado “Que tipo de ciência é, afinal, a Psicanálise?": 
A querela dos métodos: Aqui recorreremos à análise que propõe PaulLaurent Assoun em seu livro Introduction à l'Épistémologie Freudienne. Discutindo o que denomina "fundamento monista" da Psicanálise - a crença de Freud num único tipo de ciência, cujo método é válido para qualquer ciência particular - Assoun se refere à célebre "querela dos métodos" (Methodenstreit), que teve lugar na Alemanha no final do século XIX e no início do XX. Em síntese, trata-se do seguinte: haveria basicamente dois tipos de objeto para o saber, os naturais - existentes sem que o homem tenha parte em seu surgimento e em seu modus operandie os históricos ou culturais, ou seja, tudo aquilo que resulta da vida em sociedade e caracteriza a existência humana. Disciplinas como a História, a Economia, a Filologia ou a Etnologia lidam com realidades culturais, qualitativamente diversas dos corpos físicos ou dos organismos vivos que são o assunto da Astronomia, da Física, da Química e da Biologia. Há entre "humano" e o "natural" uma diferença ontológica, e, para a respeitar, é necessário o emprego de métodos diversos no estudo de cada uma destas regiões do real. (...).

Compreendida então a oposição entre ciências da Natureza e ciências do Espírito, voltemos a Freud. Não é comum encontrar, em seus escritos, a expressão Geisteswissenschaften, até porque a Psicanálise é para ele uma Naturwissenschaft. É necessário então tentar compreender por que ele pensa assim(...). Ora, não é a interpretação aquilo que singulariza a Psicanálise, na busca do sentido inconsciente de nossas produções mentais? Como então compreender a enfática posição de Freud quanto ao caráter de ciência natural da Psicanálise? Como incluir numa ciência deste gênero a prática da interpretação, própria de um campo cuja especificidade Freud faz questão de não levar em conta - não que a ignorasse, pois os debates da Methodenstreit lhe são contemporâneos?

Outra visão é a do filósofo Wilhelm Windelband que, em 1894, propôs as noções de idiográfico e nomotético, procurando demarcar as relações entre as 
Como a epistemologia, os seminários clínicos e a psicopatologia psicanalítica podem contribuir para a psicopatologia fenomenológica.

dimensões singulares e universais na produção do conhecimento. Windelband (1894) parte de uma discordância com relação à distinção proposta por Dilthey entre ciências naturais e humanas. A discordância ocorre por Windelband acreditar que Dilthey baseia-se em uma distinção que não se sustentaria, ou seja, a distinção estrita entre natureza material e natureza psíquica. "Segundo ele, a Psicologia seria justamente o desmentido dessa possibilidade, o fiel da balança para proposições classificatórias da ciência uma vez que a natureza dos fenômenos com os quais lida a impede de se adequar a categorias classificatórias mutuamente excludentes" (Simão, L. M, 2011, p. 2-3). Por fim, para ele, em todo pensamento científico, o aspecto chave é a relação entre o particular e o geral. Essa relação é, entretanto, rompida quando se coloca as leis gerais de um lado e os fatos históricos particulares de outro. “Em síntese, conforme aponta Lamiell (1998), a classificação de Windelband é metodológica, uma vez que os mesmos sujeitos podem ser objetos de investigação nomotética ou idiográfica: nomotético e idiográfico são, então, adjetivos qualificadores da natureza do conhecimento pretendido pelo pesquisador, e não do nível analítico possível ou qualidade do objeto (pessoa, grupo, organismo, etc.)" (Simão, L. M, 2011, p. 3). Para os nossos propósitos, hoje vale questionar se é assim mesmo que as coisas se dão quando temos pela frente o desafio de fazer aparecer em um só quadro as dimensões singulares e as universais de um dado fenômeno. A seguir, procurarei ilustrar esse debate a partir das discussões que se colocam contemporaneamente para uma psicopatologia psicanalítica.

\section{Uma psicopatologia psicanalítica contemporânea}

Percebo que há uma busca progressiva de um equilíbrio dinâmico entre a grande angular das construções teóricas, generalistas dos quadros psicopatológicos e o foco preciso do retrato fechado de um rosto, o "retrato psíquico" de um ser humano. Uma busca que apresenta, simultaneamente, os enquadres gerais e, por assim dizer, universais que organizam o pensamento 
psicanalítico e os detalhes singulares de várias situações clínicas que marcam o cotidiano de um analista. Com isso, procura-se revalorizar a ideia de estruturas psíquicas, mas sem perder de vista a importância dos modos singulares de funcionamento psíquico. Não há o retorno à ideia de estruturas fechadas, comum tanto na rígida tradição de certa nosologia psiquiátrica quanto em algumas abordagens psicanalíticas, mas a necessária valorização das organizações psicopatológicas e das regularidades reencontradas em diferentes casos clínicos. Mais do que isso, reconhecendo a importância dos autores em Psicanálise que souberam valorizar o caráter processual do psiquismo, busca-se afirmar que diferentes estruturas psicopatológicas (neurose e psicose, por exemplo) podem conviver como núcleos específicos em um mesmo sujeito.

Nesta visão contemporânea da Psicanálise, a Psicopatologia é central na medida em que faz a necessária mediação entre a clínica em sua singularidade e a metapsicologia (o modelo mais abstrato e generalizador de teorização). Essa ideia precisa ser valorizada. Há aqui o reconhecimento de que é fundamental existir um elemento mediador entre o que há de singular nas experiências clínicas e o que há de universal nas elaborações metapsicológicas. Com isso, sugiro que a compreensão psicopatológica deve trazer em si um pouco do desejo generalizante da grande angular metapsicológica, ao lado do reconhecimento da singularidade do retrato psíquico de um sujeito, ou como escreveu Marion Minerbo (2009, p. 39) em um livro recente: "A teoria psicopatológica tem duas faces: uma voltada para a clínica, isto é, para a apreensão do universo subjetivo do analisando; outra, voltada para a metapsicologia, o que nos permite compreender como seu psiquismo cria aquele universo subjetivo singular em que ele se move".

Uma das teorizações mais potentes na Psicopatologia psicanalítica contemporânea é a que busca a elucidação clínica e conceitual das neuroses e das não-neuroses. As estruturas neuróticas e não-neuróticas são definidas como as duas grandes formas de subjetividade e de sofrimento psíquico estudadas pela Psicanálise. Essa classificação foi sugerida por André Green. O psicanalista francês reúne sob o título de não-neuroses várias formas de adoecimento 
Como a epistemologia, os seminários clínicos e a psicopatologia psicanalítica podem contribuir para a psicopatologia fenomenológica.

psíquico marcadas por um elemento comum, ou seja, as falhas presentes na constituição do "Eu”. Para Green, são considerados quadros não-neuróticos os estados-limite, as psicoses brancas, as patologias do vazio e os distúrbios narcísico-identitários, entre outros. É uma tentativa de incluir, em um só grupo, diferentes manifestações clínicas que vão dos quadros depressivos às compulsões e adições. Para ele, há uma clara insuficiência no pensamento freudiano quanto à metapsicologia e à clínica das estruturas não-neuróticas. As teorizações que se seguiram à de Freud não produziram unanimidade no campo. Trata-se, portanto, de construir uma nova teoria a partir da experiência clínica imposta pelos novos quadros psicopatológicos. Green procurou elaborar uma proposta teórica (uma metapsicologia dos limites) que pudesse fornecer a base para o trabalho com pacientes ditos não-neuróticos. De início, sugere a complementação da teoria pulsional freudiana pela teoria de relações de objeto, principalmente a partir do legado Winnicottiano. Tratava-se de afirmar a inseparabilidade do par pulsão-objeto para compreender a constituição e o funcionamento psíquicos. No entanto, poucos anos antes de morrer, Green propôs a "teoria dos gradientes". Sem abandonar a pulsão e o objeto como par inseparável, Green passa a reconhecer um limite na aproximação entre as teorias que enfatizam o "polo subjetal" e as que enfatizam o polo objetal", considerando a utilização dessas teorias de modo alternado sem a obrigatoriedade de uma articulação. Com a teoria dos gradientes, Green procura preservar as incongruências entre as teorias propondo que cada uma pode ser útil para explicar certos fenômenos, ainda que haja entre elas diferenças incontornáveis. Green caminha, assim, de uma busca de complementaridade para a aceitação de que é mais produtivo trabalhar com a suplementação de polos ou com a tensão entre polos. Relação suplementar como sugere o filósofo francês Jacques Derrida - ou então de uma dialética sem síntese - como propõe Merleau-Ponty (a partir de Heráclito de Éfeso) entre subjetividade e intersubjetividade. 


\section{Como construir um pensamento clínico que considere simultaneamente os planos intrapsíquicos e intersubjetivos?}

Entendo que para a valorização de um pensamento clínico que ponha em relevo tanto as dimensões psicopatológicas como metapsicológicas na sua forma de conduzir o trabalho terapêutico, o elemento fundamental para o ensino e a transmissão é o espaço dos seminários clínicos.

O seminário clínico está entre o trabalho individual de supervisão e a discussão de cunho teórico mais generalizador. Permite que se trabalhe o mais próximo possível da experiência e com um mínimo de saturação teórica. Permite, também, fazer a ligação entre prática e teoria por meio do desenvolvimento de um pensamento clínico. O pensamento clínico é a condição privilegiada de criação de teorias sob medida - o que inclui teorias psicopatológicas, teorias da técnica e mesmo metapsicológicas - a partir de campos de experiência singular. Mas só funciona se for possível manter o rigor e o vigor da teoria, sem se dirigir, no entanto, para um "encharcamento" teórico. O pensamento clínico é, acima de tudo, uma criação teórica da dupla analista-paciente, ou do campo clínico formado pela dupla.

No seminário clínico é a própria criação das teorias sob medida que se torna o objeto de uma troca entre pares cujo objetivo é duplo: o de facilitar a emergência das teorias sob medida exigidas pelo caso em exame e o de expandir o alcance teórico clínico da experiência singular, tirando dela a contribuição para a formação do pensamento clínico de outros colegas. Acima de tudo, em termos psicanalíticos, entendo que o seminário clínico favorece a consideração simultânea das dimensões intrapsíquicas em questão no caso, com as dimensões intersubjetivas próprias da construção de um campo transferecialcontratransferencial. 
Como a epistemologia, os seminários clínicos e a psicopatologia psicanalítica podem contribuir para a psicopatologia fenomenológica.

\section{Considerações finais}

Para finalizar, quero retomar algumas das ideias de cunho epistemológico que apresentei no início. O exemplo da "Escala de Waelder"2 (escala de abstração crescente, da dimensão mais próxima da prática à criação de conceitos e de uma teoria), pode nos ajudar nesse propósito. A escala de Waelder é composta por seis níveis: a) o primeiro nível é o dos dados da observação clínica; b) o segundo nível é o das interpretações clínicas; c) o terceiro é o das generalizações clínicas, ou seja, as construções para o caso; d) o quarto, o da teoria clínica; e) o quinto, o da metapsicologia; f) e, por fim, o sexto é o das concepções filosóficas gerais. Parte-se da dimensão imediata sobre uma determinada sessão com um paciente e chega-se a elaborações gerais, com o maior grau de abstração possível, com a pretensão de possuir validade universal para todo e qualquer ser humano. Poderíamos pensar, em um exemplo extremo como este, que o ponto de partida da produção de conhecimento, ou o seu objeto, é a observação de uma determinada situação clínica e os resultados, serão diferentes níveis de construção de teoria (é claro que alguma teoria, possivelmente, estaria já presente como fundamento da primeira observação clínica, mesmo que o pesquisador não se dê conta disso); mas o centro da transmissão do conhecimento está em outro nível, naquele que denomino aqui de Seminários Clínicos.

Ou como sugere Mezan (2014, p. 558-559):

A bem dizer, a Psicanálise tal como Freud a concebe teoriza em dois níveis diferentes. O primeiro é este mais geral, em que surgem as grandes

2 Robert Waelder (1990-1967), psicanalista austríaco radicado nos Estados Unidos a partir de 1938 apresentou essas ideias em uma resenha de um livro editado em 1959, que reunia as conferências de um simpósio interdisciplinar realizado em 1958 na Universidade de New York sobre o tema "Psicanálise, Método Científico e Filosofia". 
hipóteses sobre o inconsciente, as pulsões, o conflito defensivo, a angústia e outros elementos do "acontecer psíquico". Aqui estamos no domínio da universalidade ou da generalidade, e o que a teoria apresenta é uma visão do ser humano como movido por forças que desconhece, tendo ao mesmo tempo que lhes oferecer alguma gratificação e restringir tal gratificação aos limites do permitido pela vida em sociedade (...)

Tudo isso refere, porém, ao plano da universalidade, ou seja, à teoria geral sobre o homem que constitui a parte mais abstrata da Psicanálise. No entanto, há no programa freudiano um outro plano de teorização, mais próximo da prática terapêutica: é o que visa a construir uma teoria específica sobre aquele indivíduo, o paciente que busca tratamento. Esta teoria se baseia no que ele relata sobre sua vida e no que dela manifesta nas condições da transferência: são estes os "dados sobre os quais vai operar a imaginação do analista. Cabe a ele não apenas interpretar um a um os elementos que vão surgindo, mas ainda reconstruir a cadeia provável de eventos que resultou naqueles sistemas, naquelas fantasias e demais particularidades daquela pessoa. O trecho da conferência 35 que compara o trabalho do analista ao do cientista menciona ambas as atividades: a interpretação de aspectos isolados ("aprendemos ora aqui, ora ali, algo novo, mas as partes não formam um conjunto coerente"), e a reconstrução que situa cada elemento no seu lugar ("as descobertas isoladas se organizam num conjunto bem ajustado, e tem-se a visão de uma parte do acontecer psíquico")(...)

Aqui também o objetivo é construir uma hipótese "idiográfica", de modo a dar conta de por que o Homem dos Ratos é obcecado por ratos e não por moscas, da razão por que o pequeno Hans teme os cavalos e não as aranhas, do motivo pelo qual Schreber delira como delira e não de outra forma ou com outros conteúdos. A originalidade de Freud consiste em realizar esta tarefa com os recursos da explicação, e não com os da compreensão, no sentido que definimos atrás para estes conceitos: é combinando as teorias gerais da Psicanálise (inconsciente, conflito psíquico, papel do Édipo, ação das defesas) com as circunstâncias únicas 
Como a epistemologia, os seminários clínicos e a psicopatologia psicanalítica podem contribuir para a psicopatologia fenomenológica.

daquela vida (experiências infantis, traumas, fixações evolutivas, intensidade das forças em presença) que chega a uma reconstrução plausível."

Aproveito as ideias de Robert Waelder e a "escala de Waelder", assim como a longa citação do texto de Renato Mezan, para indicar a necessidade de se criar permanentemente pontes entre os diferentes níveis de teorização ou de construção de conhecimento em psicanálise. Daí o valor que atribuo aos seminários clínicos (à construção coletiva de um caso clínico) na transmissão de um pensamento clínico e no ensino da psicanálise. E, mais especificamente, na transmissão de modos de formação de um pensamento clínico que trabalhe simultaneamente com o intrapsíquico e o intersubjetivo a partir da discussão coletiva de casos, que servem para reinventar constantemente a teoria geral e construir uma teoria sob medida para cada caso clínico.

\section{Referências bibliográficas:}

Bernet, R. (2013) Force-Pulsion-Désir. Une autre philosophie de la psychanalyse. Paris : J. Vrin.

Lamiell, J.T. (1998) 'Nomothetic' and 'Idiographic' - Contrasting Windelband's understanding with contemporary usage. Theory and Psychology, 8, 23-28.

Mezan, R. (2014) “Que tipo de ciência é, afinal, a Psicanálise?”. In: Mezan, R. O Tronco e os Ramos. São Paulo: Companhia das Letras, p. 543-575.

Merleau-Ponty, M. (1948 [1966]) “Le Metaphysique dans l'homme”. In: Sens et non-sens. Paris: Nagel. Gallimard.

(1960) "Le Philosophe et la Sociologie". In: Signes. Paris:

Minerbo, M. (2009) Neurose e não-neurose. São Paulo: Casa do Psicólogo.

Pélicier, Y. (1991) "Présentation de la édition française". In: Wolfgang Blankenburg, La perte de l'évidence naturelle. Paris: PUF. 
Schafer, R. (1983) The Analytic Atitude. New York: Basic Books.

Simão, L. M (2011) Ciência idiográfica, ciência cultural. In: 7. Congresso NorteNordeste de Psicologia. Salvador, Bahia, Brasil, maio de 2011. Mesa Redonda: Ciência idiográfica, historicidade e semiose na Psicologia atual.

Waelder, R. (1962) "Psychoanalysis, Scientific Method and Philosophy"- Journal of the American Psychoanalytic Association, vol. 10, p. 617-637.

Windelband, W. (1894) "Rectorial Address Strasbourg, 1894". In: History and Theory. vol. 19, no. 2 (Feb., 1980), p. 169-185. 